\title{
«Le Courrier balzacien» 35
}

\section{Marco Stupazzoni}

\section{(2) OpenEdition}

10 Journals

\section{Edizione digitale}

URL: https://journals.openedition.org/studifrancesi/13767

DOI: $10.4000 /$ studifrancesi. 13767

ISSN: 2421-5856

\section{Editore}

Rosenberg \& Sellier

\section{Edizione cartacea}

Data di pubblicazione: 1 août 2018

Paginazione: 336-337

ISSN: 0039-2944

\section{Notizia bibliografica digitale}

Marco Stupazzoni, ««Le Courrier balzacien» 35», Studi Francesi [Online], 185 (LXII | II) | 2018, online dal 01 août 2018, consultato il 16 novembre 2021. URL: http://journals.openedition.org/studifrancesi/ 13767 ; DOI: https://doi.org/10.4000/studifrancesi. 13767

Questo documento è stato generato automaticamente il 16 novembre 2021.

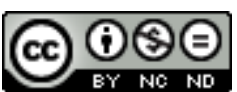

Studi Francesi è distribuita con Licenza Creative Commons Attribuzione - Non commerciale - Non opere derivate 4.0 Internazionale. 


\title{
«Le Courrier balzacien» 35
}

\author{
Marco Stupazzoni
}

\section{NOTIZIA}

«Le Courrier balzacien», nouvelle série, 35, février 2016, 75 pp.

1 Michael TILBY (Titres romanesques et noms propres chez Balzac, pp. 5-19) fornisce una puntuale e attenta disamina dello statuto e della funzione del titolo nell'opera di Balzac considerando la genesi e l'evoluzione di questo genere di «invenzione» in relazione alla specifica natura tematica e strutturale delle singole opere narrative. Per dirla con Cl. DUCHET, la titrologie balzachiana, che prevede il ricorso frequente a nomi propri di persona, non possiede i caratteri della fissità: al contrario, le continue esitazioni dell'autore riflettono sovente l'esigenza profonda di «trouver un titre qui marche de pair avec une composition souvent hétérodoxe» (p. 9) e di porre l'accento, orientando in tal modo la ricezione del lettore, sulla valorizzazione di tutto ciò che è individuale $\mathrm{e}$ particolare. Nel caso di Balzac, la titrologie, come l'onomastica, «se révèle [...] une activité bien hasardeuse» (p. 19), in quanto il titolo balzachiano - che raramente (fatta eccezione per Gobseck) designa i grandi personaggi reparaissants della Comédie humaine - «revêt un assortiment de formes ainsi que de nombreuses particularités au sein de chacune d'entre elles, ce qui entrave toute tentative de typologie formelle» (p. 18).

2 Éric BORDAS (Linguistique du nom propre dans le roman, pp. 20-26) riflette sulla problematica del nome proprio sotto il profilo linguistico con un riferimento particolare al contesto del discorso letterario, del «discours narratif romanesque sujet (et objet) de fiction» (p. 22). L'A., auspicando lo sviluppo di un approccio genetico allo studio dell'onomastica letteraria balzachiana, osserva che la particolarità unica del nome proprio nel romanzo consiste nell'essere «fonction et indice» (p. 27) e ritiene che Balzac, sempre particolarmente attratto dalla rilevanza dei nomi propri, «a toujours manifesté de la curiosité pour les mots en tant que signes matériels» (p. 24). 
3 Anne-Marie BARON (Les noms chez Balzac: parcours d'une recherche, pp. 27-38) studia il valore simbolico dei nomi propri nei romanzi balzachiani: attraverso l'uso sistematico dell'anagramma, Balzac «réussit à décliner interminablement sa propre identité» (p. 29) nei diversi personaggi delle sue finzioni narrative. La modernità della scrittura balzachiana rivela, «par ses jeux sur les noms propres», la profondità «intertextuelle et intratextuelle de La Comédie humaine» sia dal punto di vista spazio-temprale sia sotto la prospettiva storico-filosofica e, in alcuni casi, addirittura mistica.

4 Nicole MOzET (De Hérédia a Férédia. «Une lettre de différence», pp. 39-43) focalizza la sua attenzione sul foglio n. 9 del manoscritto de La Grande Bretèche, dove Balzac censura il nome di Hérédia sostituendolo con quello di Férédia. Questo «remords de plume» (p. 40) rimanda a una vicenda intimamente (e quasi inconfessabilmente) legata alla vita familiare dello scrittore (un presunto amore adulterino della madre) e «rend fluide un patronyme trop solidement ancré dans le passé de l'écrivain» (p. 41).

5 Moez LAHMEDI (Raphaël de Valentin, un nom talismatique, pp.44-52) mette in luce l'importanza assunta, ne La Peau de chagrin, dalla «appropriation onomastique dans l'appréhension de la dimension mystique» (p. 45).

6 Lucette BESSON (Balzac poète, pp. 53-65) offre un esauriente ritratto di Balzac poeta e analizza la sua concezione originale, moderna e dinamica della poesia. Per Balzac, il poeta «mobilise toute son énergie, toute la puissance de son regard et de son intuition à explorer tous les possibles, à percer les secrets de la Nature, de la Vie, de l'homme, de Dieu» (p. 65).

7 Completano le pagine del fascicolo i seguenti contributi: J. HOUBERT, Dans les catalogues de vente... (pp.66-67); Hemingway ou «Balzac le jeune» (p. 68); Loris CHAVENETTE, Balzac, Waterloo et «Le Napoléon du peuple» (pp.69-73); A.-M. BARON, Hommage au comte André Ciechanowieck (p. 74). 